\title{
Treatment of oesophageal perforation
}

\author{
D. L. FROGGATT A NDA. J . GUNNING \\ From the Nuffield Department of Surgery, Radcliffe Infirmary, Oxford
}

An oesophageal leak, produced as the result of instrumental perforation, spontaneous rupture, foreign body or oesophago-intestinal anastomotic dehiscence, is a complication which every surgeon has to deal with from time to time.

This paper presents the management of oesophageal leaks as seen in patients admitted to the Nuffield Department of Surgery at Oxford. There was a total of 33 perforations in the upper, middle, and lower portions of the oesophagus. These perforations were all caused by instruments. Foreign body perforations - the commonest cause of perforation in the pharynx and cervical oesophagus-were not seen, as these cases are dealt with by the Ear, Nose, and Throat Department. There were 17 oesophageal leaks resulting from oesophago-intestinal anastomotic dehiscence, four 'spontaneous' perforations of the oesophagus, and 13 oesophageal leaks following primary anastomotic repair of oesophageal atresias (Tables I to VI).

Until 1940, perforation of the oesophagus was accompanied by a high mortality. Subsequently it became recognized that early surgical intervention with closure of the perforation reduced this mortality. Recently a number of reports of patients treated conservatively suggests that a lower morbidity and mortality may be achieved than in those cases treated surgically, e.g., Mengoli and Klassen (1965) treated 21 cases conservatively with one death-a mortality of $5 \%$; Shapiro (1965), of Detroit, reported 24 cases without a fatality.

A major factor in the successful treatment of oesophageal perforation is early diagnosis. A perforation should be suspected in patients with persistent chest or upper abdominal pain after endoscopy, oesophageal dilatation, paraoesophageal operation, or severe vomiting. Perforation is as likely to occur with experienced as with inexperienced surgeons, and often the examination appears to have been simple.

Chest pain, often substernal and posterior, radiating to either shoulder or the abdomen, is usually severe and causes dyspnoea, cyanosis, and varying degrees of 'shock'. Surgical emphysema with crepitus in the neck, face, and chest may be ir present and is associated with thoracic and $\underset{\perp}{N}$ cervical oesophageal perforations. It is rarely 은 present when the 'abdominal' part of the oeso- phagus is perforated (see below). Fortunately, the $z$ diagnosis is in most cases apparent when the patient awakens from the anaesthetic. An erect chest radiograph will confirm the diagnosis by revealing mediastinal and cervical emphysema and a right or left hydropneumothorax. If there is any doubt, $2 \mathrm{oz}$. of dilute gastrografin taken by mouth, followed by a lateral chest film five minutes later, will show a perforation but not necessarily its site. This examination does not disturb the patient and can be done in the ward with a portable $x$-ray apparatus.

The perforation may have been apparent at the time the endoscopy was done, and an embarrassing situation arises when one has to explain to a patient, who has come in as a day case for diagnostic oesophagoscopy, the reason for tubes and a painful chest incision. This type of case, together with those in whom the diagnosis is made within a few hours, will usually be cured by thoracotomy and closure of the perforation. Definitive surgery must be done as soon as the $\delta$ diagnosis of a perforation is made. Infection and cellulitis of the mediastinal tissues occur so rapidly that delay makes surgery difficult.

The success or failure of direct surgical treatment is influenced by the pathological condition demanding endoscopy. It is occasionally possible, when a perforation has occurred above a carcinoma or peptic stricture, to resect the lesion at the time thoracotomy is done for the perforation. It is commoner for the perforation to act as a coup de grâce, and, not to put too fine an edge on it, a kindness.

There is another group of patients who may be discharged home because there are no symptoms or signs to suggest oesophageal perforation. These present, up to 10 days post-oesophagoscopy, with dysphagia and a large, painful swelling in the neck due to a retro-oesophageal (Fig. 1) abscess. It is 


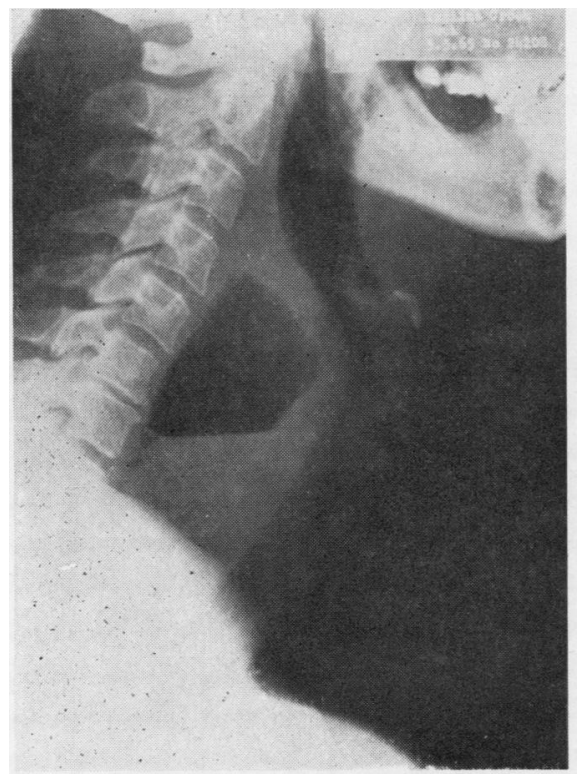

FIG. 1. Large retro-pharyngeal abscess.

doubtful whether a true perforation ever existed in these patients. We suggest that the mucous membrane just above or at the cricopharyngeus has been breached, together with bruising of the muscle, or a small perforation over a prominent osteophyte has occurred. Infection has resulted and spread to the cervical tissues as a cellulitis, which, in turn, becomes an abscess which tends

T A B LE I

OESOPHAGEAL PERFORATIONS FOLLOWING ENDOSCOPY, BOUGINAGE, INSERTION OF MOUSSEAU-BARBIN, CELESTIN, AND SOUTTAR'S TUBES (1958-1965)

\begin{tabular}{|c|c|c|}
\hline $\begin{array}{l}\text { Age range } \\
\text { No. of oesophagoscopies } \\
\text { No. of perforations } \\
\text { Non-malignant cases } \\
\text { Malignant cases }\end{array}$ & $\begin{array}{l}\cdots \\
\cdots \\
\cdots \\
\cdots\end{array}$ & $\begin{array}{r}5 \text { days to } 87 \text { years } \\
1,750 \\
6 \\
27\end{array}$ \\
\hline Total & $\ldots$ & 33 \\
\hline $\begin{array}{l}\text { Mortality } \\
\text { Non-malignant } \\
\text { Malignant .. }\end{array}$ & $\begin{array}{l}. \\
\therefore\end{array}$ & $\begin{array}{l}16 \%(1) \\
40 \%(26)\end{array}$ \\
\hline
\end{tabular}

T A B L E I I

ANALYSIS OF 33 ENDOSCOPIC OESOPHAGEAL PERFORA-

\begin{tabular}{|c|c|c|c|c|}
\hline & & & Non-malignant & Malignant \\
\hline $\begin{array}{l}\text { Site } \\
\text { Upper third } \\
\text { Middle third } \\
\text { Lower third }\end{array}$ & $\begin{array}{l}\cdots \\
\therefore\end{array}$ & \begin{tabular}{l|}
$\cdots$ \\
$\cdots$ \\
$\cdots$
\end{tabular} & $\begin{array}{l}3 \\
1 \\
2\end{array}$ & $\begin{array}{r}\overline{23} \\
\end{array}$ \\
\hline $\begin{array}{l}\text { Treatment } \\
\text { Conservative } \\
\text { Surgery } \\
\text { Combined }\end{array}$ & $\therefore$ & \begin{tabular}{l|l} 
& \\
$\cdots$ & \\
$\cdots$ & \\
$\cdots$ &
\end{tabular} & $\begin{array}{l}2 \\
2 \\
3\end{array}$ & $\begin{array}{r}25 \\
1 \\
-\end{array}$ \\
\hline
\end{tabular}

to spread down the posterior mediastinum. These lesions resolve with incision and drainage of the abscess. Larger perforations in this area are usually immediately obvious and do well with exploration and suture.

An oesophageal perforation may present as an abdominal emergency. The history is that a benign or malignant stricture in the lower third of the oesophagus has been dilated. Several hours later, after a symptomless post-anaesthetic period, the patient presents as an acute abdomen with rigidity and often pain in the back. What has happened here is that the bougie has perforated the oesophagus, usually posteriorly, at the gastrooesophageal junction and entered the lesser sac. These perforations are difficult to locate and to treat because of the pathological changes already present. Dilatation of the lower oesophagus in achalasia of the cardia with the Negus bag can lead to an insignificant perforation which later presents as a subphrenic abscess (Barrett, 1966).

Tables I and II show our experience with instrumental oesophageal perforations.

Spontaneous rupture of the lower oesophagus is rare and usually presents as an acute abdomen. It should always be considered when a patient who has the signs and symptoms of an acute abdomen is operated upon and no lesion is found in the abdomen to account for the symptoms. The abdomen should not be closed until a perforated oesophagus has been excluded. The diagnosis can often be made at this stage by the anaesthetist, because he will almost certainly have inflated the patient's lungs with oxygen prior to intubation, and much of the gas will pass down the oesophagus through the perforation and rise up the mediastinum to the supraclavicular fossae to be palpated there as crepitus.

Spontaneous rupture of the oesophagus may occur in the healthy oesophagus, in one weakened by inflammation, or as a terminal event in the chronically ill patient.

Rupture is almost always abrupt in onset, with no symptoms previously referable to the oesophagus, but it may also occur insidiously in debilitated and chronically ill patients, especially if there is a fungus infection of the oesophagus. The rupture usually occurs at the lower end of the oesophagus and the tear is linear and in the longitudinal axis. Two main factors operate to cause spontaneous rupture of the oesophagus: (1) increased intraluminal pressure in the oesophagus ; (2) peptic oesophagitis. The increased intraoesophageal pressure is usually due to vomiting and retching, and commonly there is an attempt 
on the part of the patient to suppress the vomit, e.g., to protect the carpet or to get away from company. Acute rupture of the oesophagus may occur without retching or vomiting. Conte (1966) describes two cases of acute rupture of the oesophagus associated with forceful swallowing in patients suffering from dysphagia.

The tear will vary in length and is usually sited about 2 to $5 \mathrm{~cm}$. above the cardia. It may be in the middle or upper third of the oesophagus. The perforation is usually longitudinal and the muscular defect is commonly smaller than the mucosal defect. This is an important factor to remember when repairing the defect-the mucosal defect must be clearly defined. In $70 \%$ of cases the left postero-lateral wall is most affected. The rupture may be difficult to find and the manœuvre described below will reveal its position. Oesophagoscopy should be done pre-operatively, because this will reveal the site of the tear and may also reveal unsuspected oesophageal pathological changes.

About $25 \%$ of cases of spontaneous rupture are diagnosed pre-operatively, the most common misdiagnosis being perforated peptic ulcer. The difficulty in diagnosis occurs because of the rarity of the condition, and mention has been made of the need to exclude this condition when faced with a negative laparotomy. A surgeon should be able to diagnose the condition over the telephone. The combination of a fit (usually) man, who suddenly vomits and is seized with a severe epigastric or substernal pain, together with rapid respiration, increasing shock, cyanosis, abdominal rigidity, and subcutaneous emphysema, is diagnostic of spontaneous rupture of the oesophagus. Radiologically, the most simple important investigation is an erect chest film. This will exclude subdiaphragmatic air and it may reveal mediastinal or cervical emphysema or the presence of an effusion or hydropneumothorax.

If treated in under 12 to 15 hours, a thoracotomy and direct suture will usually be sufficient, otherwise thoracic toilet and conservative treatment as described below are all that can be done.

Table III shows our series of spontaneous rupture of the oesophagus. The case requiring conservative treatment had had the perforation for 24 hours.

Foreign bodies may cause a perforation of the oesophagus, particularly when the foreign body is a bone. Often the perforation occurs as the result of repeated attempts at removal through the oesophagoscope. In other cases the foreign body is
T A B L E I I I

TRAUMATIC SPONTANEOUS RUPTURE OF THE OES PHAGUS (PRESSURE RUPTURE)

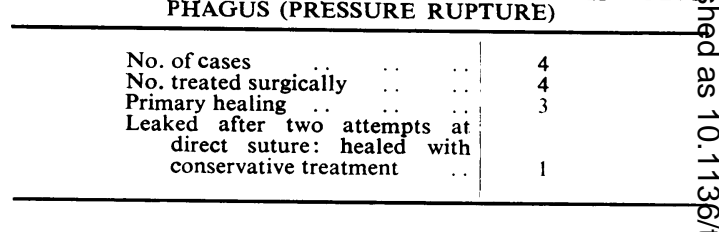

missed at oesophagoscopy, and the perforation occurs insidiously as the result of an intramurat abscess which ruptures into the pleural cavityos Treatment depends on the time interval and man be surgical or conservative, as described below.

Oesophageal leaks occurring after repair of oesophageal atresias carry a high mortality. Some of these babies may be saved by bringing the upper segment of the oesophagus out into the neck and closing the lower segment. The chilos is then fed by a gastrostomy tube till the age of 1 to 2 years, when an isolated loop of colon cano be interposed between the stomach and cervicab oesophageal stoma (Table IV).

T A B LE IV

OESOPHAGEAL ATRESIA

\begin{tabular}{lll|l}
\hline \multicolumn{3}{c|}{ OESOPHAGEAL ATRESIA } \\
$\begin{array}{l}\text { No. treated } \\
\text { No. of oesophageal leaks }\end{array}$ & $\ldots$ & $\ldots$ & $\mathbf{4 2}$ \\
\hline $\begin{array}{l}\text { No. treated surgically } \\
\text { No. treated conservatively }\end{array}$ & $\ldots$ & $\ldots$ & 2 (died) \\
No. treated with cervical oesophago- & 2 (survived) \\
stomy and gastrostomy &.. & 2 (survived)
\end{tabular}

${ }^{1}$ This is now the method of treatment in cases that leak.

Oesophageal leaks resulting from oesophago $\frac{\tilde{N}}{x}$ intestinal anastomotic dehiscence have a higho mortality, and most reports dealing with oeso 3 . phago-intestinal leaks describe one, or no, $\delta$ survivors following this complication. Our experience is shown in Tables V and VI. Most leakso occurred between the second and seventh days. $\rightarrow$ Often the effects of the leak were overwhelming and the patient died in a matter of hours. Others, $\bar{N}$ probably with smaller, slower leaks, could be taken back to the theatre and adequately drained. N Success in any oesophageal perforation treated $\mathbb{N}_{\mathcal{N}}$ conservatively will be achieved only if there is nog pathological lesion distal to the perforation, and is only complete after many trying weeks or $\frac{}{\Phi}$ months of drainage and dressings. But the effort $\stackrel{?}{-}$ should be made, particularly when a leak occurs 0 following treatment of a benign lesion.

In our series, conservative treatment has been called for when an oesophageal leak has been $\mathbb{\mathbb { D }}$ present and untreated for more than \pm 12 hours. Some of these patients have been treated by 
T A B L E V

OESOPHAGO-INTESTINAL ANASTOMOTIC LEAKS

\begin{tabular}{ll|r}
\hline $\begin{array}{l}\text { No. of cases operated on } \\
\text { (benign and malignant) }\end{array}$ & $\ldots$ & 123 \\
No. of cases that leaked &. & 17 \\
\hline
\end{tabular}

TABLE V I

ANALYSIS OF OESOPHAGO-INTESTINAL LEAKS

\begin{tabular}{|c|c|c|c|c|c|c|}
\hline \multirow[t]{2}{*}{$\begin{array}{l}\text { Carcinoma stomach } \\
\text { Post-cricoid carcinoma } \\
\text { Gastric ulcer } \\
\text { Oesophageal varices }\end{array}$} & \multicolumn{5}{|c|}{$\begin{array}{ll}\text { (Oesophago-jejunostomy) } & \cdots \\
\text { (Oesophago-jejunogastrostomy) } \\
\text { (Pharyngo-jejunostomy) } & \ldots \\
\text { (Pharyngo-gastrostomy) } & \ldots \\
\text { (Oesophago-jejunostomy) } & \ldots \\
\text { (Oesophago-jejunostomy) } & \ldots\end{array}$} & \multirow[t]{2}{*}{$\begin{array}{r}10 \\
3 \\
1 \\
1 \\
1 \\
1 \\
17\end{array}$} \\
\hline & Total & .. & $\ldots$ & . & $\ldots$ & \\
\hline $\begin{array}{l}\text { Mortality } \\
\text { No. of cases that }\end{array}$ & $\begin{array}{l}\text { Leaked } \\
\text { Died } \\
\text { Survived }\end{array}$ & $\begin{array}{l}\ldots \\
\ldots\end{array}$ & $\begin{array}{l}\cdots \\
\cdots \\
\cdots\end{array}$ & $\begin{array}{l}\cdots \\
\cdots \\
\cdots\end{array}$ & $\begin{array}{l}\cdots \\
\cdots \\
\cdots\end{array}$ & $\begin{array}{r}17 \\
10 \\
7\end{array}$ \\
\hline
\end{tabular}

thoracotomy and direct suture, but invariably the perforation has reopened after a further two to three days and then healed by conservative treatment. The perforations have usually healed without stricture; some have required occasional oesophagoscopy and dilatation later. The time taken for healing has varied from 18 days to three months. Conservative treatment is perhaps a euphemistic term to use in dealing with these lesions, and of course a certain amount of surgery is involved. What one strives for is to get an oesophago-cutaneous fistula as soon as possible by adequate and efficient drainage of the pleural cavity and mediastinum, at the same time ensuring that the lung remains fully expanded so that a track can form along the drainage tubes to the skin. In the very ill, shocked patient this will, in the first instance, mean the rapid insertion of an intercostal drainage tube into the right or left pleural cavity. Suction is applied to this tube through an underwater seal (closed drainage). The oesophagus is intubated, and gentle, continuous suction is applied to keep the oesophagus empty. Intensive antibiotic cover is started (see below).

It will be necessary, once the acute phase of shock is over, and in the less acutely ill patient, to ensure better drainage. Through a small right or left thoracotomy, the pleural cavity is cleared of fluid and fibrin, and a large-bore drainage tube is accurately positioned next to the perforation. At this time it is often difficult to find the actual perforation because of fibrin and granulation tissue. One way to demonstrate the perforation is to cover the posterior mediastinum with saline, then to ask the anaesthetist to blow down an indwelling oesophageal tube; the bubbles that

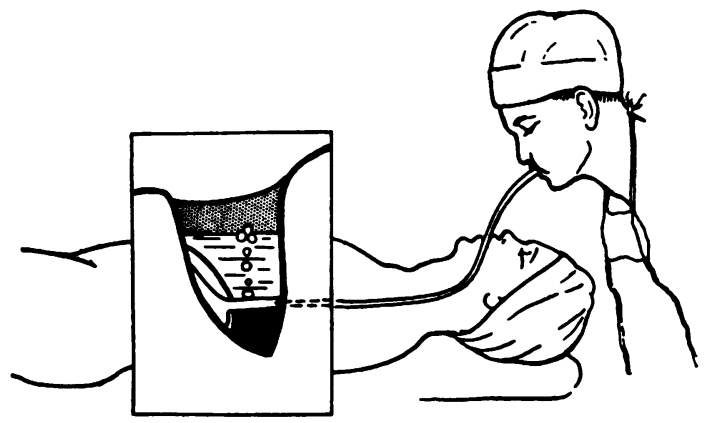

FIG. 2 (see text) Method of detecting the site of an oesophageal perforation.

ensue localize the perforation (Fig. 2). At this operation two gastrostomies are done (Fig. 3). One is used to keep the stomach empty. The reason the stomach is kept as empty as possible is because the negative pressure in the affected pleural cavity tends to suck gastric juice up the oesophagus through the perforation and so into the pleural cavity. This is especially true in infants with oesophageal atresias, in whom the anastomosis has broken down, and in adults where the perforation is in the lower two-thirds of the oesophagus. A second tube is threaded out into the jejunum and used for feeding.

Adequate intravenous replacement of fluid, calories, and protein must be given. For two to eight weeks these patients will lose a large quantity of protein and electrolyte-rich fluid and at the

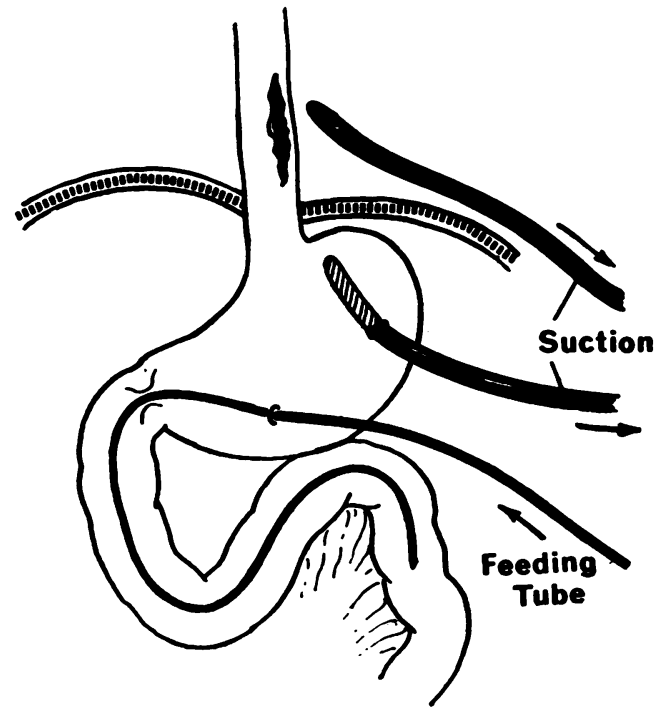

FIG. 3 (see text) More than one intercostal drainage tube may be necessary to drain the chest adequately. 
same time be subjected to slow starvation. Until recently, calories were supplied by hypertonic solutions of glucose. To obtain 1,000 calories a day would mean an infusion of 3 litres of a $15 \%$ solution of glucose. This large volume of hypertonic fluid is dangerous in patients with cardiorespiratory disease; also by injuring vascular endothelium it carries the risk of thrombophlebitis. There is now available a stable solution of fat known as intralipid ${ }^{1} ; 500 \mathrm{ml}$. of this emulsion provides 800 calories and prevents or reduces the catabolic destruction of the tissue proteins of the injured patient. Each intravenous infusion of fat must be followed by an intravenous infusion of an adequate quantity of plasma, a protein hydrolysate, or a mixture of essential amino-acids, and if alcohol $10 \%$ is added to this mixture even more calories are available. This combination of fat and protein provides an optimal supply of calories, allowing the injected protein to be completely used in the synthesis of tissue protein.

Once a good oesophago-cutaneous fistula with no intrapleural leak has been obtained (and this can be checked by gastrografin swallows), closed drainage can be changed to open drainage. The patient can now take fluid and a soft diet by mouth, even though in the early stages most of it will be found in the tube or dressing. However, provided there is no distal obstruction, each day will see a lessening of the drainage. We also believe that closure of the perforation is speeded up ; but most important of all is the fact that the patient immediately starts to feel both physically and mentally much better. The aspirate from the stomach can in the early stages be returned through the jejunostomy tube. Once the patient takes fluid by mouth, the gastrostomy tube can be clamped off. If the jejunostomy causes diarrhoea, as it usually does. it can be diminished by giving crushed codeine phosphate tablets half an hour before feeds, and also by giving the feeds slowly--in other words, by using the jejunostomy tube as if it were an intravenous drip, and by giving the feeds by slow drip during the night when the patient is asleep.

Intensive antibiotic therapy is necessary during the first 10 days. Usually penicillin and streptomycin are given parenterally, and a wide-spectrum antibiotic in syrup and fungicide should be given by mouth. 'Intralipid-fat emulsion. Manufactured by Vitram Co., Stockholm,
Sweden. Distributed by Paines \& Byrne Lid., Greenford, Middlesex

\section{SUMMARY}

The treatment of oesophageal leaks, as occurring in patients seen in the Nuffield Department of Surgery at Oxford, is described. Perforations im the cervical oesophagus may present many dayહ after the endoscopy. This type of perforation responds well to incision and drainage of the् retro-oesophageal infection. Where a foreign bod has caused cellulitis and/or perforation, removak of the foreign body and drainage of the abscess are all that is necessary (Dawes, 1964).

Leaks from the thoracic oesophagus, if diag nosed within six to twelve hours, will heal welf with thoracotomy and primary suture. Most case? are seen many hours after perforation. These are treated 'conservatively' by thoracic 'toilet' an\$ drainage. Provision is also made for continuou gastric aspiration and jejunal feeding. Intensive antibiotic therapy is necessary during the first 1 通 days. The importance of adequate calorie intak $\overrightarrow{\ell_{0}}$ with protein cover is stressed. Conservative treatos ment will be successful only if there is no obstruc ting lesion distal to the perforation.

Oesophago-intestinal anastomotic leaks ares treated 'conservatively'.

Spontaneous perforation of the oesophagus maxo present as an abdominal emergency ; the difficulty of diagnosis in this type of perforation io emphasized. Treatment will be by direct suture of conservative, depending on the time that has elapsed following perforation.

Perforations of the lower oesophagus may present insidiously as a subphrenic abscess some్ days or weeks after instrumentation. Treatmen consists in draining the subphrenic abscess.

Leaks which occur following primary anasto mosis of oesophageal atresia are best treated bys closure of the lower oesophageal segment and exteriorization of the upper segment in the neck

We thank Professor P. R. Allison for permission to include his cases in the survey. We also thank MrN N. R. Barrett for useful and helpful criticism and advice. We are grateful to Miss McLarty for the drawings and photographs.

\section{REFERENCES}

Barrett, N. R. (1966). Personal communication.

Conte, B. A. (1966). Oesophageal rupture in absence of vomiting? J. thorac. cardiovasc. Surg., 51, 137.

Dawes, J. D. K. (1964). Traumatic perforations of the pharynx an oesophagus. J. Laryng., 78, 18.

Mengoli, L. R., and Klassen, K. P. (1965). Conservative managemen of oesophageal perforation. Arch. Surg., 91, 238.

Shapiro, R. (1965). Quoted by Mengoli and Klassen. 